\title{
Prospects of detection and transformation of limiting beliefs with the help of self-coaching techniques
}

\author{
Anastasiia Dashynska \\ Wyższa Szkoła Bankowa we Wrocławiu
}

\begin{abstract}
Beliefs are considered to be solid, conscious and deliberate beliefs that perform the role of a life guide for a person. And although it is logical to think that belief should be based on an exclusively meaningful rationale, many of them are not clearly understood, while affecting the individual's perception of the external and internal world and to a great extent determine his way of life. Accordingly, false beliefs derived from childhood or formed under the influence of incorrect logic often impose restrictions on life. Working with limiting beliefs, namely their identification, analysis, and transformation, is an important step that can significantly improve the quality of life, but this is complicated by the fact that a person who does not have specific knowledge in most cases is not able to go through this process on their own. This article is devoted to the methods of complex work on yourself, aimed at awareness and transformation of false beliefs in the context of self-coaching. The article describes the stages of formation, strengthening and functioning of limiting beliefs. The author proposes a method based on a logical, sequential chain of questions, answering which a person can identify limiting beliefs and replace them with more constructive ones.
\end{abstract}

Beliefs can rightly be called the basis of human Outlook, a kind of filter through which he sees the world. Another way of defining belief sees it as a mental representation of an attitude positively oriented towards the likelihood of something being true. [1]

\section{Stages of belief formation}

Persuasion is formed from the assessments that we give to events that pass through the filters of perception into consciousness. There are several types of beliefs and stages of their formation:

- Primary beliefs arise as a result of establishing a causal relationship in response to a certain event

- Secondary beliefs appear by existing ones, when the individual already has a generalized belief, and each subsequent situation, to some extent suitable for the belief, fits with this formulation; 
- Evaluative beliefs that are based on mechanisms of reflection, when the individual evaluates events by previously established criteria and summarizes the evaluation in the form of a complex equivalent;

- Beliefs based on the experience of others, the source of which are any media, including the people around them.

It should be noted that a large number of beliefs we take out of childhood when the criticality of perception is quite low. Also, a conviction can be formed by a decision taken in a difficult situation, even if at that time it was the only adequate response.

Thus, the main sources of beliefs can be considered either their own experience or the experience of others, including education, social stereotypes, and authorities.

Most of the conclusions and generalizations made are necessary, as they remove the cognitive load in the future, but they can also form the basis of false beliefs, if they are based on the justification of fear, excuses or erroneous logic, omissions and distortion of information, since we are more often based on subjective perception than on reality. Such beliefs limit us even more and are even more difficult to change if they exist independently of the experiences, values, inner States and expectations that they are derived from. In such cases, the belief may be perceived as a kind of abstract "truth" about reality.

The belief to which a person has come through reflections and conclusions may be corrected as new experience is gained. An unconscious belief based on assumptions seems to be a "reality" confirming itself. Robert Dilts described the thought-virus as a belief that lives in isolation from other cognitive processes and the experience from which it originated, in other words, one that is not related to the context. It can be a single belief, a set of beliefs, or an idea that proves itself. [2]

Factors such as the credibility of the source of information, the context of the presentation, the intensity of reinforcement, i.e., the number of repetitions of the event and the frequency, as well as personal predisposition, also influence the process of formation and consolidation of beliefs. It should also be noted the intensity of emotions associated with the emergence of beliefs. However, a key factor will be the relevance of the new belief to the existing belief system of the individual. Thus, a belief corresponding to personal subjective ideas and values, the individual will accept without resistance, at the same time he will resist if the new belief contradicts the above-described constructs. This is due to the tendency of people to create their own "subjective social reality," dependent on perception [3]. 
In this context, we can talk about some cognitive distortions to which each of us is exposed to varying degrees. Confirmation bias is a tendency to search, interpret, focus, and remember information in a way that confirms one's biases. [4]That is, we tend to choose those proofs that support an already existing statement and ignore the proofs that argue against it. A similar cognitive distortion that also appears in this process-a Rebuttal of the bias of Disconfirmation biasmanifests itself as a tendency to avoid new information refuting ideas that contradict our current beliefs. This is due to the unwillingness to give up one's own opinion (5). Thus, we first form our beliefs, and then look for evidence to support them and refute what does not correspond to them.

Thus, deep-rooted beliefs often go unnoticed, and yet they constantly affect a person's life. Negative or inaccurate beliefs, significantly reduce the chances of the joy of daily life and selfrealization in general.

\section{Identifying limiting beliefs}

Beliefs as false beliefs to form what he calls "his truth," influence which is not easy. However, we are quite loyal to change it gradually. And the first step in the context of independent work on the problem of limiting beliefs is their identification.

Restrictive beliefs can manifest themselves in any sphere of life. They can be internal, concerning self-identification and self-assessment, or external, concerning surrounding people and processes and the world in General and are reduced to the achievement of internal purposes. However, all of them can be reduced to three main groups: hopelessness, helplessness, and worthlessness.

Hopelessness: the belief that what is desired is not achievable in principle.

Helplessness: the conviction that the desired goal is achievable, but you are not able to achieve it.

Worthlessness: the belief that you do not deserve the desired goal because of your qualities or behavior.

If a person does not understand in what area of his life appear limiting beliefs, it is proposed to consider the main ones: personal growth, health, physical environment (environment), leisure, Finance, career, family and friends, romantic relationships.

It is necessary to ask how successful a person feels in each area. The key will be what a person says to himself every day in this context and what feelings he feels at the same time. 
1. First, a person must describe the sphere itself and what it refers to, it will help him to clearly define the concept. How can you describe this area? What can you refer to it? Please highlight the keywords that will be internal values. For example, a career is an indicator that a person has achieved something in his field of activity. Keywords: success, respect, recognition. Health is when there is energy, nothing hurts. Keywords: appearance, health, mood.

2. Second, you should write out some phrases that characterize this area with the wording, as usual people get it. It is necessary to take into account the keywords written out earlier, as they are most associated with this sphere. Here the cause-and-effect relation is shown: a sequence of actions after which performance the value described by keywords can be received. A characteristic feature of this type of design is a must. To be successful, you have to work on your fears. To have recognition, it is necessary to pay maximum attention to the business.People gain respect by having experience and being hardworking (=you have to be experienced and hardworking).

\begin{tabular}{|l|l|}
\hline Value & Due diligence \\
\hline Success $=$ & you have to work on your fears \\
\hline Recognition $=$ & you must pay attention to our work \\
\hline Regard $=$ & $\begin{array}{l}\text { you have to be experienced and } \\
\text { hardworking }\end{array}$ \\
\hline
\end{tabular}

The important point is the ability to distinguish General trends (what people should do in general) from personal ones (what I should do). At this stage, inconsistencies and excuses may occur.

3. Limiting beliefs often create an unsolvable, impasse when trying to change something. A person seems to have made every effort but has not achieved a result. Successful overcoming requires the identification of the underlying limiting belief. Next, you should understand how a person feels satisfied in this area of life, given the chosen values. Does it have the chosen value sufficiently? There are some criteria - measurable ways to implement values, for example, quantitative. That is, a person determines for himself how he can understand that he has received this value. For example, recognition for him is a praise of the administration, visible result of activity, the trust of responsible tasks. 
If a person realizes that he has not received confirmation of the realization of the value, it is proposed to work out the problem by repeating the question "why," which will bring to the surface various "limiters." For example: The person admits that he does not have enough recognition. Why? Because he didn't pay enough attention to his case. Why? There was no time, strength, motivation. Why? Because he is not able to perform a large amount of complex work or is not possible to work so much time and not lose concentration or he feels that he is not able to cope with the responsibilities.

\begin{tabular}{|l|l|}
\hline Problem: & Lack of recognition \\
\hline Why? & I didn't pay enough attention to my work \\
\hline Why? & Lack of motivation \\
\hline Why? & $\begin{array}{l}\text { Unable to perform a large amount of } \\
\text { difficult work (helplessness) }\end{array}$ \\
\hline or & $\begin{array}{l}\text { It is impossible to work so much time and } \\
\text { not lose concentration (hopelessness) }\end{array}$ \\
\hline Why? & $\begin{array}{l}\text { I can not cope with the responsibilities } \\
\text { (worthlessness) }\end{array}$ \\
\hline or & I am nothing \\
\hline Why? & \\
\hline Why?
\end{tabular}

Hopelessness means that a person does not believe that the desired goal is possible in principle. It is characterized by a lack of personal responsibility and the choice of the victim's position: "whatever I do, I still will not achieve the desired. I want impossible. It's out of my control." Helplessness means that a person does not believe that he is personally able to achieve the desired result, although he recognizes the possibility of achieving. This is expressed in feelings: "Others can achieve this goal. I don't have the strength, skills, and abilities. I just can't get what I want." Worthlessness is characteristic of situations when a person realizes that he has a real opportunity to achieve the desired, but feels that he does not deserve it. Often associated with low self-esteem and a sense of its insignificance, which can be expressed as follows: "I do not represent anything. I'm unworthy. I don't need anyone. I don't deserve any good." Thus, a person chooses one of the strategies of nonachievement, behind which lies the deep personal identification. Faced with the problem of hopelessness, it is worth asking whether anything is impossible. Are there situations or people who have proven otherwise. In helplessness the main reminder that this person was able to achieve something in life (the appeal to the past). The resource for overcoming worthlessness lies in the future. 
4. To determine personal identification, please name the phrase repeated in the sphere being developed daily in the context of your own life. For example: "As I was bothered that I can't achieve career doesn't go up." It is proposed to continue the statement by what it means. For example, if a person is sure that he cannot achieve anything, it means that he is doing something wrong, which means that he is not an expert in his field of activity, then he is useless. Beliefs can be manifested in some formulas, for example," I am/am not," I should/should not," "I cannot/is not capable."

\begin{tabular}{|l|l|}
\hline I'm tired of not being able to achieve anything and my career isn't going up \\
\hline What's the meaning of that? & I'm doing something wrong. \\
\hline What's the meaning of that? & I am not an expert \\
\hline What's the meaning of that? & I'm useless \\
\hline
\end{tabular}

Thus, the total representation of beliefs is revealed, that is, a person discovers his beliefs hidden in the subconscious, concerning self-identification and perception of the situation as a whole. In this example, a person can conclude that he is not moving up the career ladder because he is afraid not to cope with his duties because he considers himself a bad specialist, which makes him feel useless.

The next step, when beliefs are realized, is their transformation.

\section{Transforming limiting beliefs}

Beliefs are extremely difficult to change using rational thinking and the usual rules of logic. It is worth considering that after we mentally create a logical rationale for our idea, we are very hard to part.

5. Consider the very belief-how it is logical and truthful. For example, from logic, a person admits that he or she rather agrees with the belief, while he or she is not sure of the answer to the question of truthfulness. It is offered to look at belief from various positions-the person would also consider if was the 5-year-old child or the elder who lived life, the representative of the opposite sex, the successful businessman and so on. This will help you not to focus on your usual point of view and expand the range.

6. The next step will be to identify the moment in which the conviction appeared. The relevant question would be whether he always thought the statement was true? If the answer is Yes, it can be assumed that this unconscious belief originates in early childhood, for example, because of the words of parents or the perception of their lives. Then it is worth considering how reliable this source of information is and how the template took then justifies itself for example, how successful were the people broadcasting the belief. In the case of a 
negative, you can find a situation or some situations, given which the conviction was fixed. This can be done by asking whether there was a time when he did not think so and what has changed in life that he believed in the belief?

7. Next, the conviction should be carefully questioned by describing situations in which it does not fully justify itself. Thus, a person gradually realizes that belief is not an unshakable truth and the only right decision.

8. In continuation, one should ask whether there are people who have opposite beliefs? How it affects them, their achievements. A positive response and illustrative examples solve the problem of hopelessness, confirming that the desired is possible in principle.

9. To overcome helplessness, an important factor is the enumeration of situations in which a person has already been able to achieve or do something, so please remember and write down such moments, as well as feelings that then experienced.

10. After analyzing the belief, a person will be able to come in response, how and in what this belief limits him, what gives and what deprives, what shortcomings of faith in him. The questions that lead to this are related to the description of a person's behavior in this area how exactly he acts and why, and please describe yourself in the context of the sphere, for example, inept or experienced, confident or timid.

11. Next, you should think about what the consequences may be if in the future a person will believe in the original belief. It is necessary to describe in as much detail as possible how it will affect him physically, morally, financially, as it will affect the environment. The process will be most effective if a person can find some good reasons.

Thus, we move on to the next key step in replacing restrictive persuasion. This point can be called the most responsible, as the previous belief is rooted and people used to perceive it as true. Accordingly, the new conviction should not raise any doubts. If he does not believe in his strength, capabilities, he is unlikely to accept a conviction as a basis. It remains to come up with a new, more appropriate belief, one that is suitable for this person and will not cause him rejection. For example, if he believed that money has only thieves, he can come to the conclusion that everyone has a chance to make good money, the main thing is to be on the alert and not be afraid, or he can decide that the money goes to specialists, so it is important to have or get new skills. The next steps will depend on what the new conviction will be.

12. Consider the advantages of using a new belief, namely how it can affect a person's life, what to change, what he will do or not do, how people will behave around.

13. This will lead to the question of how it will affect a person in the short and long term, including how it will affect the opinion about yourself.

These issues help to create positive perceptions and a positive image of the future. However, it may be to a certain extent divorced from reality due to unbelief in his power. In the context of this, it is worth asking what can stop a person and return to his former beliefs and, accordingly, find a way to avoid it. 
14. It is also necessary to think about how thoughts, words, and actions should change to correspond to the new belief since the former is already ingrained in the subconscious, it is presumably convenient for a person to follow it. Here you should also touch on the hidden benefits (secondary loss), that is significant for human needs, which he indirectly satisfies the given behavior, condition or disease. Simply put, these are benefits or useful bonuses that a person gets out of their problem. Invited to write a list answering the question, what is the advantage of the current position. You should consider each and try to refute, appealing to a new belief. For example, not moving up the career ladder, afraid not to cope with their duties, to be a bad specialist profitable, because no one will be responsible, and it will give more time to social networks and conversations with colleagues, the job will be stable and understandable, you can work less hard, so the person has stability. But when you replace the beliefs, he gets a chance to express themselves, new perspectives, respect, and therefore the achievement of value.

\section{Conclusion}

Thus, this chain of questions helps to understand the existence of limiting beliefs and their origins, the harm they cause and dispel the feelings of helplessness, worthlessness, and hopelessness that underlie most limiting beliefs, and helps to find alternatives and reinforce new beliefs. The main advantage is that a person can go this way himself without the help of specialists, which is the main advantage of self-coaching.

\section{References}

1. Primmer, Justin (2018), "Belief", in Primmer, Justin, The Stanford Encyclopedia of Philosophy, Stanford, CA: The Metaphysics Research Lab, retrieved 2008-09-19

2. Robert Dilts and 2 more

Beliefs: Pathways to Health and Well-Being

2nd Edition

ISBN-13: 978-1845908027, ISBN-10: 1845908023

3. Bless, H., Fiedler, K., \& Strack, F. Social cognition: How individuals construct social reality.. - Hove and New York: Psychology Press, 2004. — P. 2.

4. Oswald, Margit E.; Grosjean, Stefan (2004). "Confirmation Bias". In Pohl, Rüdiger F. Cognitive Illusions: A Handbook on Fallacies and Biases in Thinking, Judgement and Memory. Hove, UK: Psychology Press. pp. 79-96. ISBN 978-1-84169-351-4.OCLC55124398.

5. Edwards K. \& Smith E. E. (1996). A disconfirmation bias in the evaluation of arguments. Journal of Personality and Social Psychology, 71, 5-24.

6. David G. Myers, Social Psychology, 07/09/2012 Publisher: McGraw-Hill Education, ISBN-10: 0078035295 ISBN-13: 9780078035296 